\title{
KLF4 is a Novel Candidate Tumor Suppressor Gene in Pancreatic Ductal Carcinoma
}

\author{
Francesca Zammarchi, ${ }^{*}$ Mariangela Morelli, ${ }^{\dagger}$ \\ Michele Menicagli, ${ }^{\dagger}$ Claudio Di Cristofano, ${ }^{\dagger}$ \\ Katia Zavaglia, ${ }^{\dagger}$ Alessandra Paolucci, ${ }^{\dagger}$ \\ Daniela Campani, ${ }^{\dagger}$ Paolo Aretini, ${ }^{\dagger}$ Ugo Boggi, ${ }^{\mp}$ \\ Franco Mosca, ${ }^{\ddagger}$ Andrea Cavazzana, ${ }^{\dagger}$ \\ Luca Cartegni, ${ }^{*}$ Generoso Bevilacqua, ${ }^{\dagger}$ and \\ Chiara Maria Mazzanti ${ }^{\dagger}$ \\ From the Department of Molecular Pharmacology and Chemistry," \\ Memorial Sloan Kettering Cancer Center, New York, New York; the \\ Division of Surgical, Molecular and Ultrastructural Patbology, ${ }^{\dagger}$ \\ University of Pisa and University Hospital of Pisa, Pisa; and the \\ Division of Surgery in Uremic and Diabetic Patients, Department of \\ Oncology, Transplants and Advanced Technologies in Medicine, \\ University of Pisa, Pisa, Italy
}

Ductal pancreatic carcinoma (DPC) is a deadly disease with an incidence of 9 cases in 100,000 people per year and a mortality rate close to $100 \%$. Allelic losses in the long arm of chromosome 9 are commonly encountered in many human malignancies but no data are yet available about DPC. We screened 40 lasermicrodissected DPC samples and 6 pre-invasive lesions for 9 microsatellite mapping markers of region 9 q21.3 through 9q34.2. A small overlapping region of deletion, spanning 8 million base pairs, was identified between D9S127 and D9S105. Two genes, RSG3 and KLF4, mapped to 9q31.1 through 9q32, were further investigated. A highly significant association was found between KLF4 gene expression levels and genomic status. Similarly, absence of immunohistochemical expression of KLF4 protein was found in $86.8 \%$ cases of DPC (33/ 38). Overexpression of KLF 4 in a human pancreatic carcinoma cell line induced a significant decrease in the proliferation associated with up-regulation of p21 and the down-regulation of cyclin D1. In conclusion, we identified a novel oncosuppressor region located at the 9q 31.1-3 locus that is lost in DPC at high frequency. Loss of KLF4 expression is closely related to the genomic loss, and its restoration inhibits cancer cell proliferation, suggesting a key suppressor role in pancreatic tumorigenesis. (Am J Pathol 2011, 178:361-372; DOI: 10.1016/j.ajpath.2010.11.021)
Pancreatic cancer is the fifth leading cause of cancerrelated death in both men and women in the Western world, being responsible for $5 \%$ of all cancer-related deaths. ${ }^{1}$ The lack of reliable early diagnostic methods and effective therapeutic regimens makes the mortality rates in persons with pancreatic carcinoma virtually the same as the incidence rates. A radical surgical approach is possible in only $10 \%$ of cases, and adjuvant therapies are virtually ineffective. ${ }^{2}$ A better understanding of the molecular mechanisms leading to pancreatic tumorigenesis may provide new markers for early diagnosis and potential targets for therapeutic intervention.

Ductal pancreatic carcinoma (DPC) is by far the most common pancreatic tumor type, accounting for about $90 \%$ of all pancreatic malignancies. At present, a molecular model of DPC development has been proposed; it involves key genes, such K-ras, HER2neu, p16, p53, and DPC4 (smad4). Activating mutations in the K-ras oncogene and the overexpression of Her-2/neu gene are considered "early" genetic events because they occur in pre-invasive lesions (pancreatic intra-epithelial neoplasias, or PanINs) ${ }^{3,4}$ and are followed by homozygous deletions in the p16 tumor suppressor gene locus. ${ }^{5,6}$ Later in the tumor's progression, inactivations of p53 and DPC4 tumor suppressor genes are thought to be key events that lead to fully transformed phenotypes (carcinoma in situ, or PanIN-3). ${ }^{7-11}$

Wide genomic instability characterizes DPC, as has been documented by the large collection of cytogenetic abnormalities reported in the literature. ${ }^{12-17}$ Among these, 9p (p16 locus), 17p (p53 locus), and $18 q$ (DPC4 locus) have been reported to have been deleted in more than $60 \%$ of cases, followed by the deletions of $3 p, 4 q, 6 q, 8 p, 10 q, 12 q, 13 q, 21 q$, and

\footnotetext{
F.Z. and M.M. contributed equally to the study.

Accepted for publication September 21, 2010.

Supplemental material for this article can be found at http://ajp. amjpathol.org or doi:10.1016/j.ajpath.2010.11.021.

Current address of C.D. University, La Sapienza Rome, Polo Pontino, I.C.O.T, Latina, Italy; of A.C. General Hospital of Massa Carrara, Italy.

Address reprint requests to Chiara Maria Mazzanti, Ph.D., Division of Surgical, Molecular and Ultrastructural Pathology, University of Pisa and University Hospital of Pisa, Italy, Via Roma 57, 56100 Pisa, Italy. E-mail: c.mazzanti@med.unipi.it.
} 
22q, which have been found to have been deleted in $40 \%$ to $60 \%$ of cases. ${ }^{18}$ Allelic losses in the long arm of chromosome 9, however, have never been described in pancreatic cancer, although they are commonly encountered in many other human malignancies, including bladder, gastric, colorectal, and esophageal carcinomas. ${ }^{19-23}$ In particular, loss of heterozygosity $(\mathrm{LOH})$ analysis of $9 q$ at $9 q 13-31$ and $9 q 34$ is the most common genetic abnormality in bladder cancer, being present in $56 \%$ to $71 \%$ of cases $^{19}$ and is often observed in $25 \%$ to $50 \%$ of sporadic colorectal cancers ${ }^{21}$ and in $56.5 \%$ of gastric cancers. ${ }^{20}$ These data strongly suggest the presence of a tumor suppressor gene in this area. In fact, two very interesting genes, KLF4 and RGS3, map to this region and have been implicated in cancer development: KLF4 maps exactly to position 9q31.2, and its expression is associated with growth arrest. $^{24,25}$ It has been reported to be an essential mediator of p53 in preventing cell cycle progression following DNA damage, ${ }^{26,27}$ and KLF4 has been described as a tumor suppressor gene in colorectal, ${ }^{28}$ bladder, and gastric cancers. ${ }^{29-31}$

The RGS3 gene maps to the same area and behaves as an important negative regulator of $\mathrm{G}$ protein-coupled mitogenic signal transduction and as an activator of the mitogen-activated protein kinase signaling cascade, which is implicated in cellular proliferation, transformation, and oncogenesis. Several mammalian regulators of G protein signaling (RGSs), including RGS1, RGS2, RGS3, and RGS16, have been shown to be regulated transcriptionally by mitogens, serum, inhibition of protein synthesis, and activation of p53 tumor suppressor. ${ }^{32-34}$ These findings led us to investigate, through $\mathrm{LOH}$ analysis, how this region of chromosome 9q in DPC is involved in both infiltrative tumors and PanINs. We further studied the expression levels of both the KLF4 and RGS3 genes in relation to the structural status of the long arm of chromosome 9. The finding that there was an important involvement of the KLF4 gene in DPC led us to proceed with further molecular and functional analyses, which identified a novel and early role for KLF4 in pancreatic tumorigenesis. The dramatically negative prognosis for patients affected by pancreatic cancer inspires the development of new molecular therapeutic strategies that must be based on detailed knowledge of the molecular pathways of the disease.

\section{Materials and Methods}

The potential suppressor role in human DPC cancer tissues of the KLF4 and RGS3 genes was studied through 9q LOH analysis and mutational, methylation, and expression studies. KLF4 protein expression was measured by immunohistochemistry (IHC). Finally, KLF4 functional studies were conducted on PANC-1. Laser microdissection was used to select the neoplastic cell populations from histological sections.

\section{Tissues}

Samples of DPC and pre-invasive lesions (PanIN-1A and PanlN-2) were collected at the Division of Surgical, Molecular, and Ultrastructural Pathology at the University Hospital of Pisa (Table 1).

For expression experiments, reference normal samples were collected from explanted pancrea.

\section{9q Loss of Heterozygosity Analysis}

We used 40 microdissected, fresh DPC DNAs and matched blood samples. Tissues and blood were quickly frozen in liquid nitrogen and stored at $-80^{\circ} \mathrm{C}$. We obtained 6 microdissected pre-invasive lesions (four Pan IN-1A and two PanIN-2) from formalin-fixed and paraffin-embedded pancreatic fragments of DPC cases (Table 1). They were analyzed together with their matched blood samples.

\section{KLF4 and RGS3 Gene Expression Analysis}

We extracted mRNA from 35 and 33 DPCs, respectively, for which $\mathrm{LOH}$ data were available too (Table 1). We used 6 microdissected, freshly frozen normal pancreatic ducts for comparison analysis of KLF4 gene expression.

\section{KLF4 Mutational Analysis}

We used 17 DPC samples with available LOH data.

\section{KLF4 Promoter Methylation Status}

We used 12 DPC samples that had available $\mathrm{LOH}$ data. PANC 1 cell lines were also analyzed.

\section{KLF4 Protein Expression}

$\mathrm{IHC}$ was performed on a total of $38 \mathrm{DPC}$ samples, 17 of which had expression data available. We also analyzed 6 pre-invasive lesions (Table 1)

\section{KLF4 Functional Studies}

PANC-1 and BxPC3 cell lines originating from human pancreatic cancer cells were used.

\section{Laser Microdissection}

Histological sections $6 \mu \mathrm{m}$ thick were transferred to microscope glass slides coated with a membrane for microdissection (two to three sections per slide). Slides were stained using H\&E RNAase-free products. Sections were dehydrated (ethanol $100 \%$ for $30^{\prime}$ ) and immersed in xylene for 1 minute to facilitate their separation during the microdissection. The xylene was allowed to evaporate completely from the sections at room temperature. Microdissection was performed under direct microscopic visualization $(\times 10)$ using the Leica AS LDM system (Houston, TX). About 5000 microdissected cells were isolated and placed in $20 \mu \mathrm{LI}$ of RNA extraction mix. 
Table 1. Samples Analyzed in the Study*

\begin{tabular}{|c|c|c|c|c|c|c|c|c|}
\hline $\begin{array}{l}\text { Tissue } \\
\text { sample }\end{array}$ & TNM class & Grading & DNA-LMD & RNA-LMD & $\mathrm{LOH}$ in the SOR & KLF4 mRNA expr. & RGS3 mRNA expr. & $\mathrm{IHC}$ KLF4 \\
\hline 3-DPC & pT4 No Mx & G3/3 & * & * & HomDeL & - & + & neg \\
\hline 1-DPC & pT3 N1b M1 & $\mathrm{G} 2 / 3$ & * & * & HomDeL & - & + & \\
\hline 2-DPC & pT3 NO Mx & G3/3 & * & * & HomDeL & - & + & \\
\hline 23-DPC & pT3 NO Mx & G3/3 & * & * & HomDeL & - & - & \\
\hline 27-DPC & pT3 N1 M1 & $\mathrm{G} 2 / 3$ & * & * & HomDeL & - & + & \\
\hline 13-DPC & pT3 N1 Mx & $\mathrm{G} 2 / 3$ & * & * & $\mathrm{LOH}$ & - & l & neg \\
\hline 28-DPC & pT3 N1 Mx & $\mathrm{G} 2 / 3$ & * & * & $\mathrm{LOH}$ & - & + & neg \\
\hline 42-DPC & pT3 N1 Mx & G3/3 & * & * & $\mathrm{LOH}$ & - & + & neg \\
\hline 44-DPC & pT3 N1 Mx & $\mathrm{G} 2 / 3$ & * & * & $\mathrm{LOH}$ & - & + & neg \\
\hline 61-DPC & pT3 NO Mx & G2/3 & * & * & $\mathrm{LOH}$ & - & + & neg \\
\hline 66-DPC & pT3 N1 Mx & G3/3 & * & * & $\mathrm{LOH}$ & - & + & neg \\
\hline 67-DPC & pT3 N1 Mx & G3/3 & * & * & $\mathrm{LOH}$ & - & - & neg \\
\hline 19-DPC & pT3 N1b Mx & $\mathrm{G} 3 / 3$ & * & * & $\mathrm{LOH}$ & - & + & \\
\hline 47-DPC & pT3 N1b Mx & $\mathrm{G} 2 / 3$ & * & * & $\mathrm{LOH}$ & - & + & \\
\hline 53-DPC & pT3 N1b Mx & G1/3 & * & * & $\mathrm{LOH}$ & - & + & \\
\hline 69-DPC & pT3 N1 Mx & $\mathrm{G} 2 / 3$ & * & * & $\mathrm{LOH}$ & - & - & \\
\hline 74-DPC & pT3 NO Mx & G3/3 & * & * & $\mathrm{LOH}$ & - & - & \\
\hline 78-DPC & pT3 N1 M1 & $\mathrm{G} 2 / 3$ & * & * & $\mathrm{LOH}$ & - & - & \\
\hline 7-DPC & pT4 N1 Mx & G3/3 & * & * & $\mathrm{LOH}$ & + & + & neg \\
\hline 30-DPC & pT4 N1a Mx & $\mathrm{G} 2 / 3$ & * & * & $\mathrm{LOH}$ & + & + & \\
\hline 17-DPC & pT3 N1 Mx & $\mathrm{G} 2 / 3$ & * & * & $\mathrm{ROH}$ & - & + & neg \\
\hline 43-DPC & pT3 N1 Mx & $\mathrm{G} 2 / 3$ & * & * & $\mathrm{ROH}$ & - & + & neg \\
\hline 59-DPC & pT3 N1 M1 & $\mathrm{G} 2 / 3$ & * & * & $\mathrm{ROH}$ & - & + & neg \\
\hline 35-DPC & pT4 N1b Mx & G3/3 & * & * & $\mathrm{ROH}$ & - & + & \\
\hline 40-DPC & pT3 N1b Mx & $\mathrm{G} 2 / 3$ & * & * & $\mathrm{ROH}$ & - & - & \\
\hline 70-DPC & pT3 N1 Mx & $\mathrm{G} 2 / 3$ & * & * & $\mathrm{ROH}$ & - & + & \\
\hline 76-DPC & pT3 N1 Mx & G3/3 & * & * & $\mathrm{ROH}$ & - & - & \\
\hline 22-DPC & pT3 N1b Mx & $\mathrm{G} 2 / 3$ & * & * & $\mathrm{ROH}$ & + & + & neg \\
\hline 29-DPC & pT3 N1 M1 & $\mathrm{G} 2 / 3$ & * & * & $\mathrm{ROH}$ & + & 1 & neg \\
\hline 24-DPC & pT3 N1 Mx & G3/3 & * & * & $\mathrm{ROH}$ & + & - & pos \\
\hline 26-DPC & pT3 NO Mx & G1/3 & * & * & $\mathrm{ROH}$ & + & + & pos \\
\hline 33-DPC & pT3 NO Mx & G3/3 & * & * & $\mathrm{ROH}$ & + & + & pos \\
\hline 38-DPC & pT3 N1 Mx & $\mathrm{G} 2 / 3$ & * & * & $\mathrm{ROH}$ & + & + & \\
\hline 57-DPC & pT3 N1 Mx & $\mathrm{G} 2 / 3$ & * & * & $\mathrm{ROH}$ & + & + & \\
\hline 75-DPC & pT3 N1 Mx & G3/3 & * & * & $\mathrm{ROH}$ & + & + & \\
\hline Sample 1 & PanIN & 2 & * & & $\mathrm{LOH}$ & & & neg \\
\hline Sample 2 & PanIN & $1 \mathrm{~A}$ & * & & HomDeL & & & neg \\
\hline Sample 3 & PanIN & $1 \mathrm{~A}$ & * & & HomDeL & & & neg \\
\hline Sample 4 & PanIN & 2 & * & & $\mathrm{LOH}$ & & & pos \\
\hline Sample 5 & PanIN & $1 \mathrm{~A}$ & * & & $\mathrm{LOH}$ & & & pos \\
\hline Sample 6 & PanIN & $1 \mathrm{~A}$ & * & & $\mathrm{LOH}$ & & & pos \\
\hline 6-DPC & pT3 N1b Mx & G2/3 & * & & $\mathrm{LOH}$ & & & \\
\hline 8-DPC & pT4 N1 Mx & G3/3 & * & & $\mathrm{LOH}$ & & & \\
\hline 73-DPC & pT3 N1b Mx & G3/3 & * & & $\mathrm{LOH}$ & & & \\
\hline 85-DPC & pT3 N1 Mx & $\mathrm{G} 2 / 3$ & * & & $\mathrm{LOH}$ & & & \\
\hline 77-DPC & pT3 NO Mx & $\mathrm{G} 1 / 3$ & * & & $\mathrm{ROH}$ & & & \\
\hline DPC1 & pT3 NO Mx & $\mathrm{G} 2 / 3$ & l & l & I & l & I & pos \\
\hline DPC2 & pT3 N1 Mx & $\mathrm{G} 2 / 3$ & l & I & I & I & I & pos \\
\hline DPC3 to 21 & various & various & 1 & l & I & I & l & neg \\
\hline
\end{tabular}

*DNA/RNA was extracted from laser microdissected (LMD) neoplastic cells (frozen tissue). Six PanINs were paraffin embedded; 21 paraffin-embedded DPCs were further analyzed only for KLF4 protein expression by IHC: 2 were KLF4-positive (DPC1,2), and 19 were KLF4-negative (DPC3-21).

\section{Extraction of Nucleic Acids}

Microdissected tumor cells were resuspended in $20 \mu \mathrm{L}$ of DNA extraction buffer containing $0.005 \mathrm{~mol} / \mathrm{L}$ of Tris$\mathrm{HCl}, 0.001 \mathrm{~mol} / \mathrm{L}$ of EDTA, $1 \%$ of Tween-20, and 0.1 $\mathrm{mg} / \mathrm{ml}$ of proteinase $\mathrm{K}(\mathrm{pH} 8.0)$ and were incubated overnight at $37^{\circ} \mathrm{C}$. After proteinase $\mathrm{K}$ inactivation at $95^{\circ} \mathrm{C}$ for 10 minutes, DNA samples were ready for amplification. RNA was extracted using the RNAeasy Micro Kit (Qiagen, Hilden, Germany) as recommended by the manufacturer.

\section{Analysis of Loss of Heterozygosity}

We used a panel of nine highly polymorphic microsatellite markers for deletion mapping of the chromosome 9 long arm. Details about the cytogenetic localization of the microsatellite markers used are shown in Table 2. Primer information was obtained from the National Center for Biotechnology Information Genome Database (http:// www.ncbi.n/m.nih.gov/mapview/) and Ensembl Database (http://www.ensembl.org). The region framed by the D9S152 and D9S66 markers spans approximately 50 
Table 2. Frequency of LOH on 9q in DPC and in PanINs

\begin{tabular}{|c|c|c|c|c|c|c|}
\hline Marker name & Mapping position & $\begin{array}{c}\text { Genetic position } \\
(\mathrm{Mpb})^{*}\end{array}$ & $\begin{array}{c}\mathrm{N}^{\circ} \mathrm{LOH} / \text { informative } \\
\text { DPCs }\end{array}$ & $\begin{array}{c}\mathrm{N}^{\circ} \mathrm{LOH} / \text { informative } \\
\text { PanINs }\end{array}$ & $\begin{array}{l}\mathrm{LOH}(\%) \\
\text { DPCs }\end{array}$ & $\begin{array}{l}\mathrm{LOH}(\%) \\
\text { PanlNs }\end{array}$ \\
\hline D9S152 & $9 q 21.32$ & 83,36 & $13 / 37$ & $0 / 5$ & 35 & 0 \\
\hline D9S127 & $9 q 31.1$ & 103,6 & $16 / 38$ & $2 / 4$ & 42 & 50 \\
\hline D9S53 & $9 \mathrm{q} 31.1$ & 104,6 & $13 / 34$ & $1 / 4$ & 38 & 25 \\
\hline D9S105 & $9 q 31.3$ & 111,3 & $19 / 37$ & $5 / 6$ & 51 & 83 \\
\hline D9S106 & $9 q 32$ & 113,3 & $12 / 36$ & $1 / 5$ & 33 & 20 \\
\hline D9S1823 & $9 \mathrm{q} 33.2$ & 120,7 & $6 / 27$ & $0 / 2$ & 22 & 0 \\
\hline D9S125 & $9 q 34.13$ & 132,1 & $8 / 31$ & $3 / 6$ & 26 & 50 \\
\hline D9S1199 & $9 q 34.13$ & 132,8 & $10 / 37$ & $1 / 5$ & 27 & 20 \\
\hline D9S66 & $9 q 34.2$ & 133,7 & $8 / 32$ & $0 / 3$ & 25 & 0 \\
\hline
\end{tabular}

*Ensembl DataBank.

million base pairs. PCR reactions were performed on a final volume of $30 \mu \mathrm{L}$ containing $2 \mu \mathrm{L}$ of DNA lisate, 2 $\mathrm{mmol} / \mathrm{L}$ deoxynucleotide triphosphate (Eurobio, Les Ulis, France), $250 \mathrm{ng} / \mu \mathrm{L}$ of each forward primer (Applied Biosystems, Foster City, CA) and reverse primer (Eurofins MWG Operon, Ebersberg, Germany), $1.5 \mathrm{mmol} / \mathrm{L} \mathrm{MgCl2}$, 1X PCR gold buffer, and $1 \mathrm{U}$ AmpliTaq Gold (PE Biosystems, Foster City, CA). Fluorescently FAM-labeled forward primers (Applied Biosystems) were used for $\mathrm{LOH}$ analysis. The cycling parameters were the following: $95^{\circ} \mathrm{C}$ for 7 minutes, 40 cycles of $94^{\circ} \mathrm{C}$ for 1 minute, specific annealing temperature for 1 minute, $72^{\circ} \mathrm{C}$ for 1 minute, and a final extension step at $72^{\circ} \mathrm{C}$ for 10 minutes. The annealing temperature for each primer pair was $57^{\circ} \mathrm{C}$ except for D9S66, which was $54^{\circ} \mathrm{C}$. PCR products were diluted tenfold and then separated by capillary electrophoresis using an ABI Prism 3100 Genetic Analyzer (Applied Biosystems). After electrophoresis, the raw genotype files were analyzed using GeneScan 3.5 analysis software (Applied Biosystems). LOH was defined as complete or nearly complete absence of one allele $(>75 \%)$, as evidenced by direct visualization. Reactions were done in triplicate. DNA samples homozygous at the marker of interest were considered noninformative for $\mathrm{LOH}$ determination. The smallest overlapping region (SOR) was defined as the smallest region comprising common spanning deletion in the majority of tumors. Based on the SOR findings, DPC samples were subdivided into three categories and referred to as $\mathrm{LOH}$ (cases with loss of heterozygosity in at least one informative locus); HomDel (cases with loss of both alleles); or $\mathrm{ROH}$ (cases with retention of heterozygosity in all informative loci).

\section{Mutational Analysis of KLF4}

PCR primers were designed using the Primer3 program (http://frodo.wi.mit.edu/primer3/) on the flanking regions of coding exons of the KLF4 gene. GeneID 9314 was used as reference sequences (primer sequences available on request) for KLF4. The annealing temperature was $57^{\circ} \mathrm{C}$. The mutational status was determined by direct sequencing as follows: PCR product was purified using Montage PCR96 Cleanup Kit (Millipore, Billerica, $M A)$. Six $\mu \mathrm{L}$ of purified product were then sequenced using BigDye Terminator v3.1 Cycle Sequencing Kit (Ap- plied Biosystems). The sequencing reaction contained 3 $\mu \mathrm{L}$ of purified PCR product, $2 \mu \mathrm{L}$ of BigDye Terminator Mix, $1.5 \mu \mathrm{L}$ of primer $(3 \mathrm{pmol})$, and $9 \mu \mathrm{L}$ of BigDye Terminator v3.1 Sequencing Buffer 5X. Thermal cycling conditions were 30 cycles at $96^{\circ} \mathrm{C}$ for 10 seconds, at $50^{\circ} \mathrm{C}$ for 5 seconds, and at $60^{\circ} \mathrm{C}$ for 3 minutes. Unincorporated primers and dye terminators were removed using Montage-SEQ96 Sequencing Reaction Cleanup Kit (Millipore). Eight $\mu \mathrm{L}$ of purified samples with $8 \mu \mathrm{L}$ of $\mathrm{Hi}-\mathrm{Di}$ Formamide (Applied Biosystems) were denatured at $95^{\circ} \mathrm{C}$ for 3 minutes. Sequencing was performed on an ABI PRISM 3100 Genetic Analyzer (Applied Biosystems).

\section{Reverse Transcription PCR of the KLF4 and RGS3 Genes}

Four $\mu \mathrm{L}$ of total RNA (approx. $200 \mathrm{ng}$ ) were used for cDNA synthesis, using ImProm-II Reverse Transcription System (Promega, Madison, WI). A measure of $3 \mu \mathrm{L}$ of the resulting CDNA was included in each PCR reaction. Primer sequences for the respective CDNA were as follows: 5'-TTGGCTTCGTTCTTCTCTTCGTTGACTा-3' and 5'-CGGAGGATGGGTCAGCGAATT-3' for KLF4; 5'-CGGGCAAGGCAGACAA-3' and 5'-GCCTTGGATGCCATCT-3' for RGS3; 5'-GGTGAAGGTCGGAGTCAACGGA-3' and 5'CCATGGTGGTGAAGACGCCAGTGGACTC-3' for GAPDH. Annealing temperatures were $55^{\circ} \mathrm{C}$ per KLF4 and GAPDH and $57^{\circ} \mathrm{C}$ for RGS3. PCR products were separated by electrophoresis through an ethidium bromide-stained $2 \%$ agarose gel and visualized in UV light. Gels were photographed and the bands were scanned as digital peaks. The areas of the peaks were calculated in arbitrary units using the public domain NIH Image software from the National Institutes of Health (http://rsb.info.nih.gov/ij). The value of GAPDH mRNA was used as a normalizing factor to evaluate the relative expression levels of KLF4 mRNA.

\section{Sodium Bisulfite Sequencing of KLF4 Promoter}

DNA methylation was analyzed by sodium-bisulfite sequencing, using EZ DNA Methylation Kit (Zymo Research, Orange, CA) according to manufacturer's instructions. Bisulfite deaminates and converts cytosine residues to uracil, leaving methylated cytosines unmodified. 
A 184-bp fragment in the KLF4 promoter was amplified from bisulfite-modified DNA. Primers (forward: 5' GATTATAAATTAAGGGGAGAGTGGG-3'; reverse: 5'TCCCTAAAAAATAACCATATACCAAAA-3') were designed using MethPrimer Software (http://www.urogene. org/methprimer/index1.html) in a region lacking CpG dinucleotides to amplify both methylated and unmethylated alleles. The amplified fragment (annealing temperature, $57^{\circ} \mathrm{C}$ ) spanned from nucleotide-2341 to nucleotide-2157, corresponding to KLF4 transcription start site and included $10 \mathrm{CpG}$ sites. PCR products were sequenced as previously described.

\section{KLF4 Protein Expression by Immunohistochemistry}

DPCs were analyzed by tissue microarrays constructed using the ATA 100 Chemicon International system. Two areas of normal tissue and three different tumor areas represented each sample in the tissue microarrays. Two 5 - $\mu \mathrm{m}$-thick tissue microarray sections were placed onto SuperFrost Plus glass slides and immunostained in an automated system (BenchMark XT, Ventana Medical Systems, Tucson, AZ ). The commercially available rabbit polyclonal anti-GKLF antibody ( $\mathrm{H}-180$, Santa Cruz Biotechnology, Santa Cruz, CA) was used at a dilution of 1:150. Normal intestinal mucosa specimens were used as positive control for KLF4 expression; pancreatic cells were considered immunopositive when staining intensity was comparable to that of intestinal cells. The $\mathrm{IHC}$ results were scored as positive, when nuclear staining was present in more than $10 \%$ of cells or negative when nuclear staining was absent or present in less than 10\% of tumor cells.

\section{KLF4 Functional Study}

\section{Cell Line and Culture}

The human pancreatic cancer cell line PANC-1 and BxPC3 were a generous gift of Dr. Gary Schwartz (Memorial Sloan-Kettering Cancer Center, New York, NY) and were grown in RPMI 1640 supplemented with 10\% fetal bovine serum, $100 \mathrm{U} / \mathrm{ml}$ penicillin, and $100 \mu \mathrm{g} / \mathrm{ml}$ streptomycin.

\section{Plasmid Construction and Transfection}

The full-length KLF4 cDNA was subcloned into the eukaryotic expression vector pcDNA3.1 (Invitrogen), and the insert was verified by sequencing. For transfection, PANC-1 or BxPC3 were plated into either 12-well or 48well plates and allowed to adhere for 12 hours. Lipofectamine 2000 (Invitrogen) was used for transfecting the cells with either pcDNA3.1-KLF4 or pCDNA3.1 alone. Cells were cultured for 72 (or 96) additional hours after transfection.

\section{Antibody and Western Blotting}

Whole-cell lysates were prepared by directly lysing cells in hot Laemmli sample buffers (4\% SDS, $20 \%$ glycerol, $10 \%$ 2-mercaptoethanol, $0.004 \%$ bromo-phenol blue, $0.125 \mathrm{M}$ Tris-HCl). For Western blot analyses, $30 \mu \mathrm{g}$ of cell lysate were diluted on sample buffers and resolved on $8 \%$ SDS-PAGE, transferred to a PDVF membrane and probed with anti KLF-4, anti-p21 (Santa Cruz Biotechnology), anti-cyclin D1 (Cell Signaling) or anti $\alpha$-tubulin antibodies (Sigma-Aldrich, St. Louis, MO).

\section{Proliferation Assay}

Quantification of cell growth was determined in triplicates and in quadruplicates for the 72- and 96-hour experiments, respectively, using the CellTiter 96 AQueous One Solution Cell Proliferation Assay (Promega). The absorbance at $490 \mathrm{~nm}$ was measured using a microplate reader.

\section{Cell Count Assay}

At the end of the transfection treatment, cells were trypsinized and counted by using a hemocytometer.

\section{Trypan Blue Assay}

At the end of the transfection treatment, cells were trypsinized, stained with trypan blue, counted using a hemocytometer, and scored as dead or alive.

\section{TUNEL Assay}

A terminal deoxynucleotidyl transferase-mediated dUTP nick-end labeling (TUNEL) assay was performed using an Apoptosis Detection Kit (Roche, Werk Penzberg, Germany) in accordance with the manufacturer's instructions. Slides were analyzed under a fluorescent microscope. TUNEL-positive (GFP-positive) nuclei were counted in three randomly selected microscopic fields per slide and were expressed as a percentage of the total nuclei counted. At least 1000 nuclei were counted on each slide.

\section{Statistical Analysis}

Data were summarized using descriptive statistics, including means and SDS for continuous data or proportions for categorical data. All $P$ values were two-sided. Univariate methods were carried out using the one-way analysis of variance statistical test for continuous data. The differences were considered statistically significant when the $P$ value was less than 0.05 . KLF4 expression and frequency of LOH in KLF4 IHC and KLF4 mRNA were also compared using either the Pearson $\chi^{2}$ test or Fisher's two-tailed exact test, as appropriate. The functional studies data were analyzed for significance by either the Student's $t$-test (two-tailed) or the stratified $\chi^{2}$ test. The differences were considered statistically significant when $P<0.05$. 
A

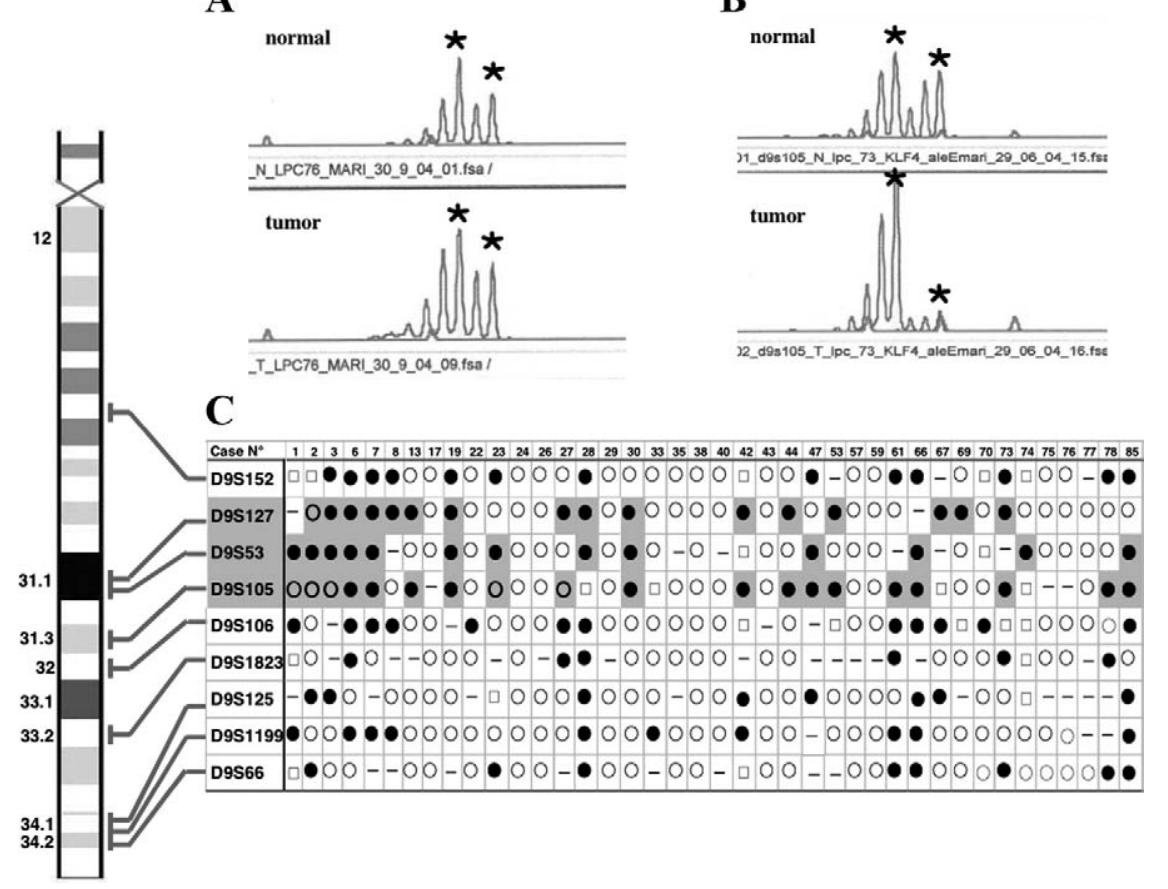

Figure 1. A: Example of retention of heterozygosity. Samples are in heterozygosity for the specific microsatellite, and the peaks represent each allele amplification product. Asterisks indicate the peaks chosen for the LOH analysis. $\mathrm{LOH}$ analysis was conducted by measuring the ratio between the two peak fluorescence values. LOH was present if the ratio was below 0.5 or above 1.5. B: Example of LOH on D9S105. C: Pattern of LOH on 9q in DPCs. (Black circles are LOH cases; grey circles are cases with homozygous deletions; white circles are cases with retention; white squares are cases with instability; - indicates noninformative cases). The SOR region is highlighted in grey.

\section{Results}

\section{A 9q Region of Frequent Allelic Loss Characterizes Both DPCs and PanINs}

A panel of 40 paired normal-tumor DNA samples from DPCs and 6 PanINs were assayed for $\mathrm{LOH}$ using 9 polymorphic microsatellites mapped to chromosome 9q. The results are summarized in Table 2 .

In at least one locus, $\mathrm{LOH}$ was found in $67.5 \%$ of tumor samples (27/40) and in all PanIN samples (Figure 1 and Figure 2). $\mathrm{LOH}$ frequencies varied among the markers from 22\% (D9S1823 at 9q33.2) to 51\% (D9S105 at 9q31.3) in DPCs and from 0 (D9S1823 and D9S66 at 9q33.2 and 9q34.2) to 83\% (D9S105 at 9q31.3) in PanINs. In 24 cases $(60 \%)$ there were interstitial allelic deletions, thus defining the SOR at 9q31.1-31.3, flanked by microsatellites D9S127 and D9S105 (Figure 1C). The same SOR was also present in all PanIN samples (Figure 2).

A homozygous deletion at SOR was detected in 5 of 37 informative cases of DPC (13.5\%) and in 2 of 6 PanINs. The microsatellite D9S105 appeared to be the most sensitive marker in detecting this deletion (Figure 3A).

\section{KLF4 Gene Expression is Associated with 9q Chromosomal Status and Significantly Decreases in DPC Compared to Normal Pancreatic Tissue}

KLF4 mRNA was not detected in $71 \%$ of DPC cases $(25 / 35)$. KLF4 expression was absent in $100 \%$ of cases in HomDeL (5/5) (Figure 3B); in $85.6 \%$ of cases in $\mathrm{LOH}$ (12/15); and in $46.6 \%$ of cases with $\mathrm{RHO}(7 / 15)$. The overall expression pattern was significantly associated $(P$ $=0.002$ ) with the genomic asset, indicating a strong relationship between 9q31.1-3 loss and lack of KLF4 expression (Figure 3D). The $\mathrm{LOH}$ analysis was not conducted on the normal pancreatic ducts, under the assumption that they do not carry any chromosomal alterations.

All normal cases showed similar levels of mRNA (Figure $3 \mathrm{C})$. Strong statistical significance $(P=0.002)$ was found to characterize the difference in KLF4 expression between all DPCs and normal tissue. In fact lack of KLF4 mRNA was detected in $71 \%$ of DPC samples (25/35), whereas $100 \%$ of normal pancreatic ducts (6/6) showed KLF4 expression (Table 3). No mRNA was available for the six PanIN samples.

\begin{tabular}{|c|c|c|c|c|c|c|}
\hline CaseN & 1 & 2 & 3 & 4 & 5 & 6 \\
\hline Dgsi5? & 0 & 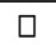 & 0 & 0 & 0 & 0 \\
\hline DSS127 & 0 & - & 0 & 0 & 0 & 0 \\
\hline D9S53 & 0 & 0 & ( & - & 0 & 0 \\
\hline D9S105 & 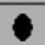 & 0 & 0 & 1 & $\square$ & 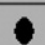 \\
\hline Desios & 0 & 0 & 0 & 0 & - & 0 \\
\hline DEsiges & 0 & 0 & 0 & 0 & 0 & 0 \\
\hline Dosizs & 0 & 0 & 0 & 0 & 0 & 0 \\
\hline DPSi199 & 0 & 0 & 0 & 0 & 0 & 0 \\
\hline D:SE6 & 0 & 0 & 0 & 0 & 0 & 0 \\
\hline
\end{tabular}

Figure 2. Pattern of LOH on 9q in PanINs (black circles are cases with LOH; grey circles are cases with homozygous deletions; white circles are cases with retention; white squares are cases with instability; — indicates noninformative cases). The SOR region is highlighted in gray. 
$\mathbf{A}$

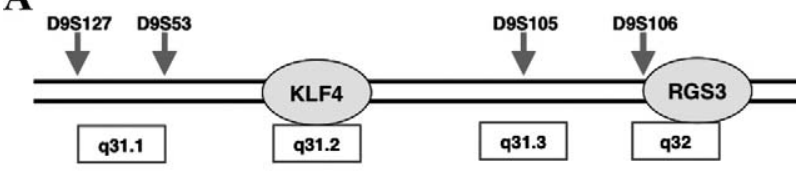

B

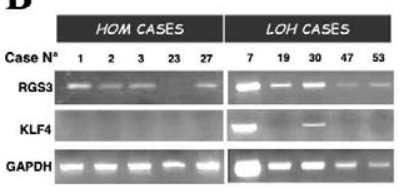

C

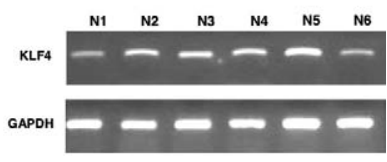

D

KLF4 mRNA expression and genomic setting

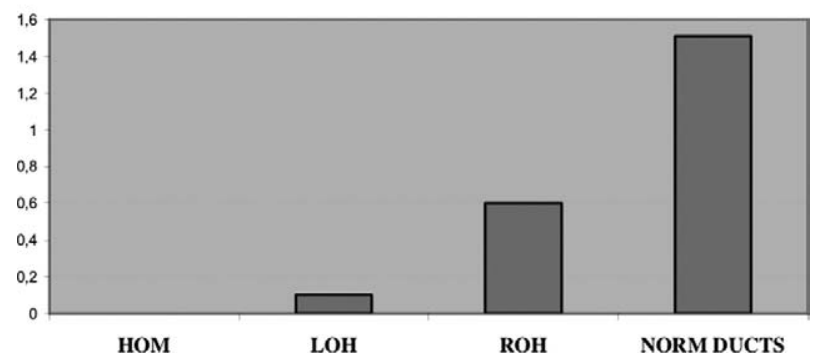

Figure 3. A: Schematic representation of RGS3 and KLF4 loci. B: Example of RT-PCR in $5 \mathrm{HomDel}$ and $5 \mathrm{LOH}$ cases. C: Expression of KLF4 in normal pancreatic ducts. D: mRNA expression analysis of the KLF4 gene in HomDel, $\mathrm{LOH}, \mathrm{ROH}$, and normal ducts. GAPDH was chosen as an internal control gene. Each histogram represents the ratio of the KLF 4 and the GAPDH level of mRNA expression. There is a significant association with a $P$ value $=0.002$ between the amount of KLF4 mRNA expression and genomic status.

\section{RGS3 Gene Expression Is not Associated with 9q Chromosomal Status}

RGS3 expression was absent only in $25 \%$ of DPCs (8/33), and there is no significant difference regarding the $9 q$ chromosomal status. In fact, RGS3 mRNA was not detected in $20 \%$ of th HomDeL cases (1/5) (Figure 3B); in $28.6 \%$ of cases with $\mathrm{LOH}(4 / 14)$; or in $21.4 \%$ of $\mathrm{ROH}$ cases (3/14). Based on these data, it is unlikely that RGS3 could be involved as a tumor suppressor gene in DPC.

\section{The KLF4 Gene in DPC}

We subsequently investigated KLF4 in more detail, because its expression was absent in all HomDel cases and in the majority of $\mathrm{LOH}$ cases. The entire coding region of KLF4 gene was directly analyzed in 17 microdissected primary tumors: 5 HomDel (T-1, T-2, T-3, T-23, T-27); 9

Table 3. Difference in KLF4 Expression between 35 Ductal Pancreatic Carcinomas and 6 Normal Tissues*

\begin{tabular}{cccc}
\hline & KLF4 mRNA + & KLF4 mRNA - & Total \\
\hline $\begin{array}{c}\text { Ductal pancreatic } \\
\text { carcinoma } \\
\begin{array}{c}\text { Normal } \\
\text { pancreatic } \\
\text { ducts } \\
\text { Total }\end{array}\end{array}$ & $10(29 \%)$ & $25(71 \%)$ & 35 \\
\hline
\end{tabular}

${ }^{\star} 71 \%$ of ductal pancreatic carcinomas had no expression of KLF4 compared to 0 in normal pancreatic ducts $(P$ value $=0.002)$.
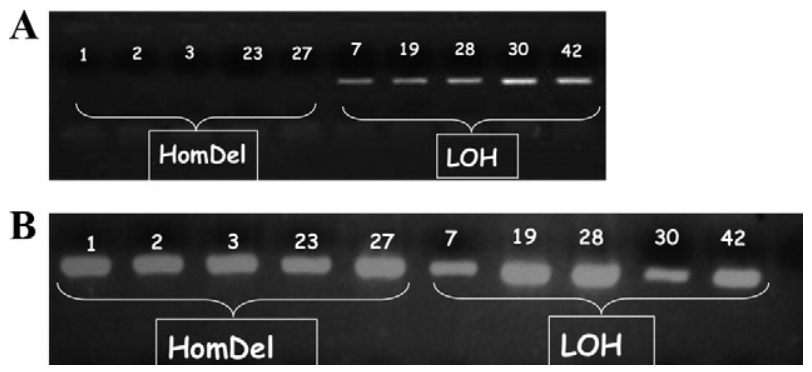

Figure 4. A: Five samples of HomDel could not be amplified for any of the genomic coding exons of the KLF4 gene, whereas all LOH and ROH samples were successfully amplified (figure shows only a few representative samples). B: The Braf gene was successfully amplified in all five HomDel samples and in a few representative $\mathrm{LOH}$ and $\mathrm{ROH}$ samples as a control for the genomic DNA used to support the result of a KLF4 locus homozygous deletion.

LOH (T-6, T-7, T-13, T-19, T-28, T-30, T-47, T-53, T-67); and $3 \mathrm{ROH}$ (T-24, T-33, T-75). All five HomDeL cases fail to amplify any KLF4 coding sequences, whereas all four coding exons were successfully amplified and sequenced in both $\mathrm{LOH}$ and $\mathrm{ROH}$ cases (Figure 4, A and $\mathrm{B}$ ). No mutations were found in these last cases. One sample ( $T-19)$ showed 1 synonymous single-nucleotide polymorphism on codon 154 (gcg $>$ gct).

To further understand the mechanisms responsible for the loss of KLF4 expression in cases of DPC, we studied the methylation status of the KLF4 promoter region by bisulfite-sequencing PCR on DNA extracted from $12 \mathrm{mi}-$ crodissected DPC specimens ( $7 \mathrm{LOH} K L F 4$ - and $5 \mathrm{ROH}$ $K L F 4+)$. Sequencing of bisulfite is based on the selective deamination of cytosines to thymine following bisulfite treatment and the sequencing of subsequently generated PCR products. In contrast to unmethylated cytosine, the 5-methylcytosine does not react with bisulfite and can therefore be distinguished. The loss of cytosines to thymine along the sequence after bisulfite treatment therefore indicates the unmethylated status of the original sequence (Figure 5B). Only two of the seven KLF4-cases (28.6\%) (T-19, T-76) show the presence of cytosine nucleotides in the $\mathrm{CpG}$ island ( $\mathrm{T}-\mathrm{XX}$ is shown in Figure $5 \mathrm{C}$ ) and were considered methylated. None of the KLF4+ cases were methylated. These results suggest that hypermethylation may justify the loss of KLF4 expression in a minority of DPC samples.

\section{Significant Loss of KLF4 Protein Expression in DPCs and PanINs}

Immunohistochemistry was performed in 6 PanINs and in 38 DPCs, including 17 of those analyzed for RNA expression. Unlike normal intestinal epithelial cells, normal pancreatic ducts showed nuclear staining in only a few scattered cells. Three of six PanINs were negative for KLF4 immunostaining (Figure 6A), whereas the remaining three showed a nuclear positive staining (Figure 6B). The PanIN sample with the homozygous genomic deletion lacked expression of the KLF4 protein. Of 38 (86.8\%) DPCs, 33 lacked KLF4 protein expression (Figure 6C), whereas 5 cases exhibited strong nuclear staining (Figure 6D). 
A

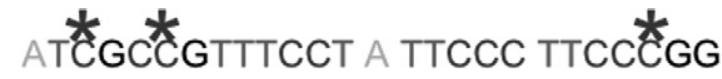

B

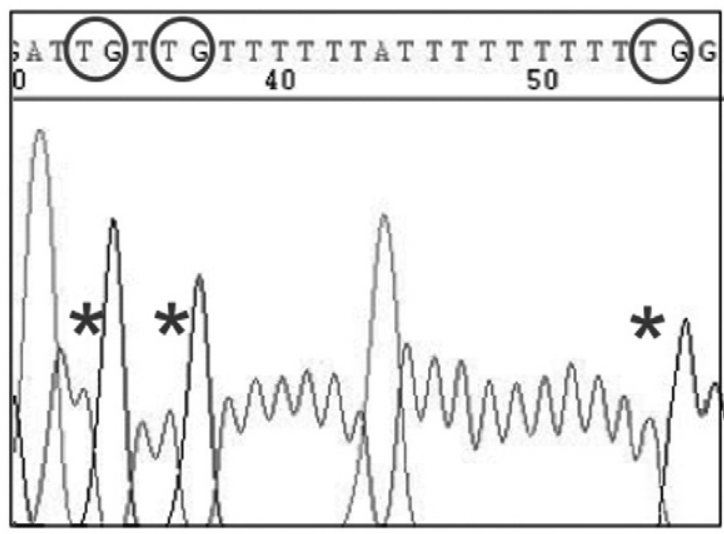

C

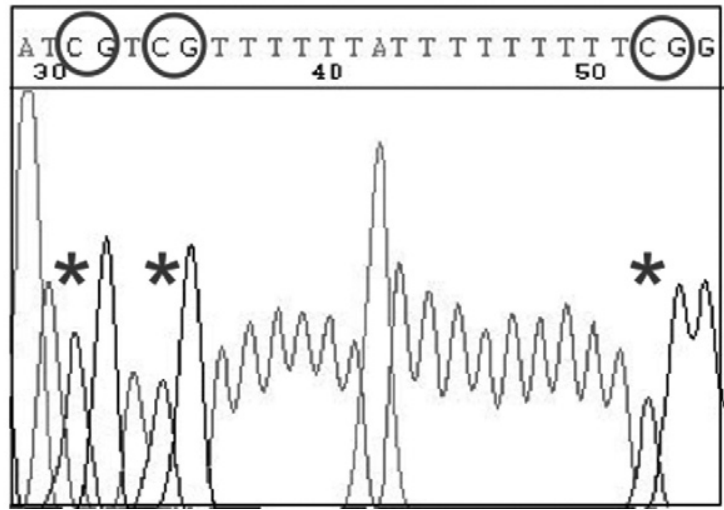

Figure 5. KLF4 promoter methylation analysis. A: A fragment of KLF4 5 UTR showing orginal nucleotide sequence before bisulfite treatment; cytosines of $3 \mathrm{CpG}$ dinucleotides are circled with an asterisk. B: Electropherogram of an unmethylated case. C: Electropherogram of a methylated case.

Matching of mRNA and $\mathrm{IHC}$ expression data in 17 cases showed a significant association between $\mathrm{IHC}$ and mRNA data $(P$ value $=0.03) ; 14$ DPC cases lacked KLF4 protein expression and 3 showed positive nuclear staining (Table 4). Of the 14 KLF4-negative samples, 11 also

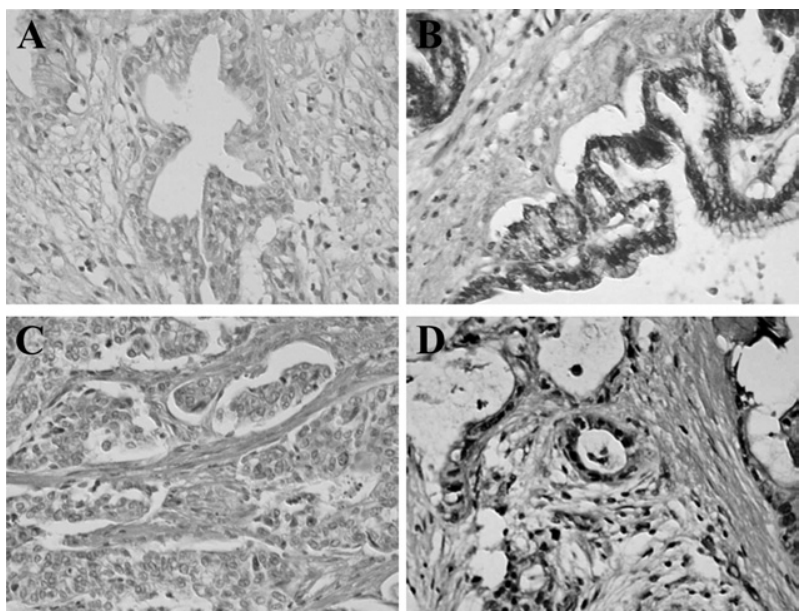

Figure 6. Immunostaining with anti-KLF4 antibody: negative (A) and positive (B) PanINs; negative (C) and positive (D) DPCs ( $400 \times$ magnification).
Table 4. Matching of mRNA and IHC Expression Data*

\begin{tabular}{lccc}
\hline & KLF4 mRNA - & KLF4 mRNA + & Total \\
\hline KLF4 IHC - & $11(79 \%)$ & $3(21 \%)$ & 14 \\
KLF4 IHC + & $0(0 \%)$ & $3(100 \%)$ & 3 \\
Total & 11 & 6 & 17 \\
\hline
\end{tabular}

${ }^{*}$ Of the samples, 17 showed matching of mRNA and IHC expression data. 14DPCs lacked KLF4 protein expression (IHC -), and 11 cases lacked KLF4 mRNA (mRNA -); 3 expressed KLF4 mRNA (mRNA +). The remaining 3DPCs expressing the KLF4 protein $(\mathrm{IHC}+)$ were also KLF4 mRNA $+(P=0.03)$.

lacked KLF4 mRNA expression, whereas in 3 cases (21\%) the absence of KLF4 protein was associated with normal levels of KLF4 mRNA, thus suggesting the involvement of some post-translational events.

\section{KLF4 Controls Proliferation and Viability in Functional Studies}

To address the role of KLF4 in pancreatic cells proliferation directly, we transiently overexpressed the full-length KLF4 CDNA in PANC-1, a cell line derived from a human pancreatic carcinoma of ductal cell origin. PANC-1 is considered a good in vitro model for DPC and, in our hands, did not express detectable level of endogenous KLF4 (Figure 7D, first panel). To rule out the possibility that the absence of KLF4 expression in PANC-1 is due to methylation, we analyzed the methylation status of the KLF4 promoter in DNA extracted from PANC-1 and KLF4; the results showed that they were not methylated (data not shown). On PANC-1 transfection with KFL4-expressing or control vector, cell proliferation was assessed by either cell count or the MTT proliferation assay. Indeed, KLF4 over-expression induced a significant decrease of
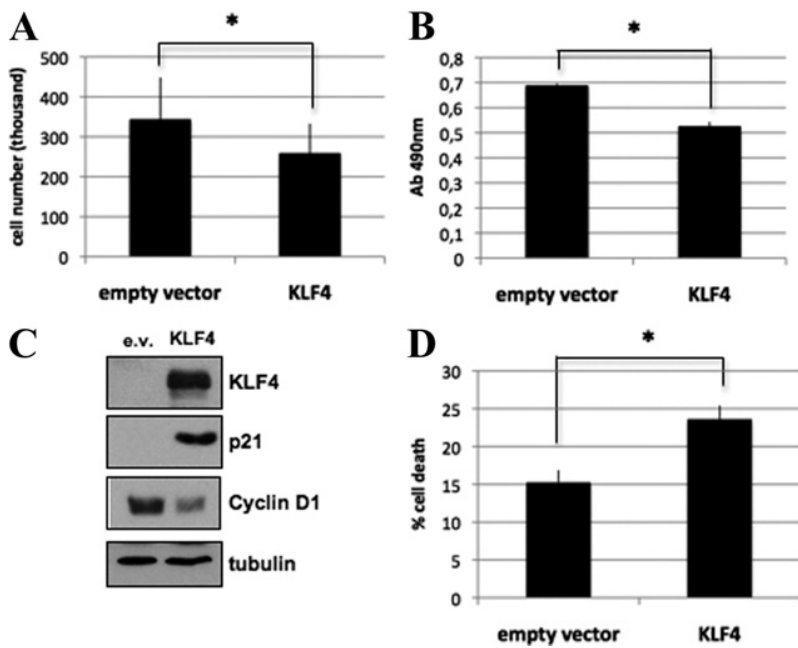

Figure 7. Effect of KLF4 on cell proliferation and viability. The following assays were performed on PANC- 1 cells 72 hours after transfection with either KLF4 or the empty-vector. A-B: Cell proliferation was assayed by either cell count or the MTT proliferation assay; columns represent mean of two independent experiments done in triplicate; bars, SD. C: Western blot analysis checked the expression level of KLF4, p21 and cyclin D1. Tubulin was used as loading control. D: Cell death was determined by trypan blue assay. Values are presented as dead/alive percent; columns represent the mean of two independent experiments done in triplicate; bars, $\mathrm{SE} * P<0.05$. 
PANC-1 proliferation in both assays (Figure 7, A and B). It is interesting that in the MTT assay, the decrease in proliferation, evident already after 48 hours of transfection $(P$ value $<0.05)$, became even more pronounced at 96 hours with a $32.4 \%$ overall reduction in proliferation ( $P$ value $<0.001$ ) (see Supplemental Figure S1A at $h t t p: / /$ ajp.amjpathol.org). There was a statistically significant decrease in cell count, with $P$ value $=0.03$. Moreover, over-expression of KLF4 in a different pancreatic cancer cell line, BxPC3, resulted in a significant decrease in cell proliferation confirming KLF4 involvement in the control of pancreatic cancer proliferation (see Supplemental Figure $\mathrm{S} 1 \mathrm{~B}$ at $h t t p: / / a j p . a m j p a t h o l . o r g)$. Next, to investigate the mechanism by which KLF4 controls cell proliferation, we looked at the expression of two known KLF4 targets involved in cell cycle progression: p21 and cyclin D1. As shown in Figure 7C, KLF4 induced a dramatic increase in p21 and, at the same time, a strong down-regulation of cyclin D1.

Finally, to further investigate the mechanism by which KLF4 controls the proliferation of pancreatic cancer cells, we looked at cell death induction in PANC-1 overexpressing KLF4. We found that KLF4 caused a significant increase in cell death as measured by the trypan blue method ( $P$ value 1,2E-06) (Figure 7D). Nevertheless, we performed a TUNEL assay to verify whether the increase in cell death was caused by apoptosis and did not find a significant difference (data not shown), suggesting that KLF4 contribution involves additional pathways for cell death.

\section{Discussion}

DPC is a deadly disease with a very poor prognosis: the overall survival at five years accounts for only $5 \%$ to $10 \%$ of all cases. ${ }^{1} \mathrm{~A}$ progression model has been proposed for pancreatic carcinoma that is similar to that for the colonic adenoma-carcinoma sequence. Pre-invasive proliferative ductal lesions called PanINs are believed to represent the morphological precursors of invasive ductal carcinoma. ${ }^{35,36}$ Identification of novel molecular markers is crucial for the development of more successful and less toxic targeted treatment strategies.

Although some molecular events leading to DPC development are already known, the cause of this aggressive behavior is still largely unclear. DPCs are characterized by high genomic instability, resulting in complex karyotypes with a large number of numerical and structural chromosomal abnormalities. Allelic losses affecting the long arm of chromosome 9 are often encountered in many human malignancies, including bladder $(71 \%),{ }^{19}$ gastric (56.5\%), ${ }^{20}$ colorectal (25\% to $\left.50 \%\right),{ }^{21}$ and esophageal carcinomas $(67 \%$ to $86 \%){ }^{22}$ Two main regions have been described; they involve the $9 q 32$ and $9 q 31$ loci. $\mathrm{LOH}$ at $9 \mathrm{q} 32$ is associated mainly with esophageal and urothelial carcinomas, whereas $9 q 31$ appears to be involved in colorectal and gastric cancers.

Here we report for the first time the high frequency of $\mathrm{LOH}$ at $9 \mathrm{q}$ in a series of 40 microdissected DPC samples. Using highly polymorphic microsatellite markers we were able to define a commonly deleted region spanning 8 Mbp and mapped at 9q31.1-31.3. The overall frequency of $\mathrm{LOH}$ in this region was $67.5 \%$. Moreover, the same analysis was carried out in a panel of six pre-invasive lesions, and we found the same pattern of deletion on $9 \mathrm{q}$. In particular, all early pre-invasive lesions (PanINs) showed LOH at 9q31; 5 DPCs of 37 informative cases and 2 of 6 informative PanIN samples demonstrated a homozygous deletion at $9 q 31.3$ Based on our results we can hypothesize that the $9 \mathrm{q} \mathrm{LOH}$ event occurs earlier than the 9p, 17p, or $18 q$ losses, ${ }^{37}$ even though the number of pre-invasive samples analyzed was small. The putative tumor suppressor gene mapped at 9q31 is probably involved in early pancreatic tumorigenesis rather than in tumor progression. This hypothesis is further supported by similar findings reported in gastric cancer, where the loss of the 9q31 region has been significantly associated with the early stages of the disease. ${ }^{20}$

A second candidate tumor suppressor gene, RGS3, also maps in this region and has also been suggested as a potential tumor suppressor. ${ }^{38-40}$ However, we were unable to detect any significant change in RGS3 expression within our series, thus excluding RGS3 as a major candidate tumor suppressor gene in our model.

On the contrary, we documented a loss of KLF4 mRNA expression in $71 \%$ of the DPCs analyzed. In particular, lack of KLF4 mRNA was documented in $100 \%, 85.6 \%$, and $50 \%$ of cases showing homozygous deletion, $\mathrm{LOH}$, and retention of heterozygosity respectively (Figure 3 ). This expression pattern was significantly associated with the genomic asset, indicating a strong relationship between 9q31 loss and KLF4 expression. Moreover, IHC analysis confirmed the loss of KLF4 protein expression in $86.8 \%$ of DPC samples. Overlapping results for $\mathrm{IHC}$ and RT-PCR were obtained in the majority of cases (14/17 cases). In three cases the presence of mRNA was not associated with protein expression, probably reflecting post-translational events (Table 4). KLF4 protein was also lacking in three of six pre-invasive lesions (Figure 6, A and B), supporting our hypothesis that KLF4 loss is an early event. However, in 2005 Prasad and colleagues conducted a microarray study on microdissected PanINs and found that KLF4 is up-regulated compared to normal pancreatic tissue. Nevertheless, this result was confirmed by RT-PCR and in situ hybridization in three of six (50\%) and five of eleven $(45 \%)$ of PanINs. ${ }^{41}$ In our study, no mRNA from PanINs was available for expression studies but we were able to conduct the $\mathrm{LOH}$ and $\mathrm{IHC}$ analyses that supported our theory of loss of the KLF4 locus and protein expression. The latter is probably due to some still unexplained posttranslational events. As a matter of fact, loss of KLF4 protein expression was recently observed in $24.4 \%$ of colorectal cancers ${ }^{28}$ and in $32.4 \%$ of primary gastric tumors. ${ }^{31}$ Downregulation of KLF4 is also significantly associated with regulation of proliferation, differentiation, and tumorigenesis of gastrointestinal epithelium. ${ }^{30} \mathrm{~A}$ recently generated conditional KLF4-knockout mouse model, specific for the gastric compartment, has shown that KLF4 can indeed function as a tumor suppressor gene; the mice developed gastric hyperplasia and polyps. ${ }^{42}$ 
The mechanisms of drastically altered KLF4 expression are still unknown. Two human colorectal cancer cell lines have been described to carry point mutations in coding exons of KLF4, ${ }^{28}$ but point mutations in KLF4 have not yet been reported in tumors and, consistently, we have not detected any mutation in the KLF4 coding sequences in our series of DPCs. The analysis of the KLF4 promoter methylation status evidenced that two of seven (28.6\%) KLF4-negative cases were methylated. Our LOH analysis at chromosome 9q31.1-32 revealed genetic loss in the $89 \%$ of KLF4 not expressing DPCs (including the two methylated cases), indicating that both genetic and epigenetic changes may cause KLF4 gene inactivation in the majority of DPCs.

This evidence is also supported by three recent reports: (1) a high frequency of $\mathrm{LOH}$ on chromosome $9 \mathrm{q} 31$ was found in human gastric cancers ${ }^{20}$; (2) the KLF4 locus was methylated and deleted in human gastric cancers ${ }^{31}$; (3) $\mathrm{LOH}$ and hypermethylation of the $5^{\prime}$-untranslated region have been associated with altered KLF4 expression and with functions in colorectal cancer. ${ }^{28}$ However, alternative mechanisms for KLF4 transcriptional inactivation may occur in the remaining $11 \%$ of KLF4 nonexpressing DPCs that don't exhibit genetic loss or promoter methylation. In the colon cancer model KLF4 may, in fact, be down-regulated by either CDX2, APC, or $\beta$-catenin. ${ }^{43-45}$

Post-transcriptional events, such as alternative splicing and alternative polyadenylation, could affect KLF4 protein levels and/or activity without having an obvious effect on total RNA levels. Although alternative splicing has not been yet described for KLF4, the relative usage of multiple KLF4 polyA sites varies in different mouse tissues and during development ${ }^{46}$; the distal sites are predicted to generate isoforms that are more stable and/or more efficiently translated. Finally, it would be interesting to explore whether miRNAs-mediated inhibition of KLF4 plays a role in pancreatic cancer because KLF4 has very recently been described as a putative target of miR-143 and miR-145. ${ }^{47,48}$

Currently, KLF4 has been added to a group of ambiguous cancer-related genes because its expression has been shown to increase in breast ductal carcinoma ${ }^{49}$ and oral squamous carcinoma. ${ }^{50}$ It has been shown that KLF4 switches between its tumor-suppressive and oncogenic modes as a function of the genetic context. Our results provide evidence for KLF4 tumor-suppressive functions in DPC, as indicated by the significant association between LOH at KLF4 locus, the loss of expression in most of the samples, the gene silencing due to promoter methylation, and the loss of protein expression through a hitherto unexplained mechanism. To further investigate a possible role of the KLF4 gene as a tumor-suppressor gene in pancreatic cancer, we performed a functional analysis in which the full-length KLF4 cDNA was transfected into a human pancreatic exocrine carcinoma cell line (PANC-1 and BxPC3), considered a good in vitro DPC model and, as in the majority of DPCs, not expressing KLF4 mRNA levels. The KLF4 promoter resulted in no methylation in PANC-1. It is interesting that overexpression of KLF4 significantly inhibits cell proliferation consis- tently in its role as a tumor suppressor in pancreatic tumorigenesis. Enforced KLF4 overexpression induced in PANC-1 a dramatic increase in p21 and, at the same time, a strong down-regulation of cyclin D1, which are two important cell cycle regulators. ${ }^{51}$ These observations indicate that KLF4 acts as a tumor suppressor and confirms the results obtained by Hu W and colleagues ${ }^{52}$ in 2009 in lung cancer cell lines. Moreover, this result is also consistent with recent findings by Wei and colleagues ${ }^{25}$ that KLF4 promotes p27Kip-mediated cell cycle arrest in vitro and attenuates tumor growth and metastasis in an orthotopic mouse model. This study was conducted on six different pancreatic cell lines, including PANC-1. Wei and colleagues ${ }^{25}$ found that KLF4 is expressed at a reduced level in PANC-1 cells, whereas in our experiment the expression of KLF4 is absent. This discrepancy, which actually is not very strong, could be due to technical reasons. Moreover, they studied the suppressive effect of KLF4 on proliferation in FG and Bx3P cells but not in PANC-1. Their analysis on PANC-1 was limited to Western blot. However, the results they obtained from the KLF4 over-expression and proliferation studies on the pancreatic cell lines support our findings in PANC-1 ${ }^{25}$ and also in $\mathrm{BxPC} 3$. It is interesting also to indicate that the same authors ${ }^{31}$ demonstrated in 2005 how, in gastric cancer, KLF4 expression induces apoptosis. Our results show also a significant increase in cell death after KLF4 over-expression. Nevertheless, when we performed a TUNEL assay to verify whether the increased in cell death was caused by apoptosis, we did not find a significant difference, which suggests that the contribution of KLF4 to pancreatic cell lines involves additional cell-death pathways.

\section{Conclusions}

We have reported for the first time a high frequency of genomic losses at the long arm of chromosome 9 in primary DCP samples. An 8-Mbp region, bounded by microsatellites D9S127 and D9S105, is lost in $67.5 \%$ of DPC samples. This event seems to occur early because it is also documented in early PanINs, suggesting a possible role in the development of pancreatic cancer for at least one gene in this region.

KLF4 maps at 9q31.3 locus and its mRNA and protein are dramatically reduced in a large majority of DPCs (71\% and $86.8 \%$, respectively). However, we could not find any point mutations in the coding sequences of the gene, and promoter hypermethylation was observed in only a minority of cases (28.6\%), so further investigations are necessary to completely understand the mechanisms responsible for KLF4 repression in DPCs.

Overall, KLF4 represents a novel gene which, being down-regulated in pancreatic cancer, could be evaluated in the development of therapeutic gene therapies for malignancies intended to be achieved through targeted gene delivery or targeted gene transcription. The use of gene substitution in cancer therapy is far from being complete; the finding of a drug that can take a suppressed gene and cause it to be re-expressed is rare. 
Nevertheless, it has recently been reported ${ }^{53}$ that a specific drug (RS5444) being tested in a phase 1/2 clinical trial to treat anaplastic thyroid cancer might be useful for treating other cancers. This drug induces the transcription of many genes and in thyroid cancer induces the expression of $\mathrm{p} 21$, which is one of the target genes of KLF4. Therefore, such findings suggest further testing of these classes of drugs, which could have significant effects on cancer biology.

\section{References}

1. Jemal A, Siegel R, Ward E, Hao Y, Xu J, Thun MJ: Cancer statistics, 2009. CA Cancer J Clin 2009, 59:225-249

2. Li CP, Chao Y, Chi KH, Chan WK, Teng HC, Lee RC, Chang FY, Lee $\mathrm{SD}$, Yen SH: Concurrent chemoradiotherapy treatment of locally advanced pancreatic cancer: gemcitabine versus 5-fluorouracil, a randomized controlled study. Int J Radiat Oncol Biol Phys 2003, 57:98104

3. Moskaluk CA, Hruban RH, Kern SE: p16 and K-ras gene mutations in the intraductal precursors of human pancreatic adenocarcinoma. Cancer Res 1997, 57:2140-2143

4. Schneider G, Schmid RM: Genetic alterations in pancreatic carcinoma. Mol Cancer 2003, 2:15

5. Wilentz RE, Geradts J, Maynard R, Offerhaus GJ, Kang M, Goggins M, Yeo CJ, Kern SE, Hruban RH: Inactivation of the p16 (INK4A) tumor-suppressor gene in pancreatic duct lesions: loss of intranuclear expression. Cancer Res 1998, 58:4740-4744

6. Caldas C, Hahn SA, da Costa LT, Redston MS, Schutte M, Seymour $A B$, Weinstein $C L$, Hruban RH, Yeo CJ, Kern SE: Frequent somatic mutations and homozygous deletions of the p16 (MTS1) gene in pancreatic adenocarcinoma. Nat Genet 1994, 8:27-32

7. Rozenblum E, Schutte M, Goggins M, Hahn SA, Panzer S, Zahurak M, Goodman SN, Sohn TA, Hruban RH, Yeo CJ, Kern SE: Tumor-suppressive pathways in pancreatic carcinoma. Cancer Res 1997, 57: $1731-1734$

8. Apple SK, Hecht JR, Lewin DN, Jahromi SA, Grody WW, Nieberg RK: Immunohistochemical evaluation of K-ras, p53, and HER-2/neu expression in hyperplastic, dysplastic, and carcinomatous lesions of the pancreas: evidence for multistep carcinogenesis. Hum Pathol 1999, 30:123-129

9. Redston MS, Caldas C, Seymour AB, Hruban RH, da Costa L, Yeo CJ, Kern SE: p53 mutations in pancreatic carcinoma and evidence of common involvement of homocopolymer tracts in DNA microdeletions. Cancer Res 1994, 54:3025-3033

10. Barton CM, Staddon SL, Hughes CM, Hall PA, O'Sullivan C, Kloppel G, Theis B, Russell RC, Neoptolemos J, Williamson RC, Lane DP, Lemoine NR: Abnormalities of the p53 tumour suppressor gene in human pancreatic cancer. Br J Cancer 1991, 64:1076-1082

11. Hahn SA, Schutte M, Hoque AT, Moskaluk CA, da Costa LT, Rozenblum E, Weinstein CL, Fischer A, Yeo CJ, Hruban RH, Kern SE: DPC4, a candidate tumor suppressor gene at human chromosome 18q21.1. Science 1996, 271:350-353

12. Hahn SA, Kern SE: Molecular genetics of exocrine pancreatic neoplasms. Surg Clin North Am 1995, 75:857-869

13. Seymour AB, Hruban RH, Redston M, Caldas C, Powell SM, Kinzler KW, Yeo CJ, Kern SE: Allelotype of pancreatic adenocarcinoma. Cancer Res 1994, 54:2761-2764

14. Hahn SA, Seymour AB, Hoque AT, Schutte M, da Costa LT, Redston MS, Caldas C, Weinstein CL, Fischer A, Yeo CJ, Hruban RH, Kern SE: Allelotype of pancreatic adenocarcinoma using xenograft enrichment. Cancer Res 1995, 55:4670-4675

15. Fujii H, Inagaki M, Kasai S, Miyokawa N, Tokusashi Y, Gabrielson E, Hruban RH: Genetic progression and heterogeneity in intraductal papillary-mucinous neoplasms of the pancreas. Am J Pathol 1997, 151:1447-1454

16. Mahlamaki EH, Hoglund M, Gorunova L, Karhu R, Dawiskiba S, Andren-Sandberg A, Kallioniemi OP, Johansson B: Comparative genomic hybridization reveals frequent gains of 20q, 8q, 11q, 12p, and $17 q$, and losses of $18 q, 9 p$, and $15 q$ in pancreatic cancer. Genes Chromosomes Cancer 1997, 20:383-391
17. Sugio K, Molberg K, Albores-Saavedra J, Virmani AK, Kishimoto $Y$ Gazdar AF: K-ras mutations and allelic loss at $5 q$ and $18 q$ in the development of human pancreatic cancers. Int J Pancreatol 1997 , 21:205-217

18. Yamano M, Fujii H, Takagaki T, Kadowaki N, Watanabe H, Shirai T: Genetic progression and divergence in pancreatic carcinoma. Am J Pathol 2000, 156:2123-2133

19. Shigyo M, Sugano K, Fukayama N, Taniguchi T, Tobisu K, Fujimoto H, Doi N, Niwakawa M, Shimamura K, Tsukamoto T, Sekiya T, Kakizoe T: Allelic loss on chromosome 9 in bladder cancer tissues and urine samples detected by blunt-end single-strand DNA conformation polymorphism. Int J Cancer 1998, 78:425-429

20. Kakinuma N, Kohu K, Sato M, Yamada T, Nakajima M, Akiyama T, Ohwada S, Shibanaka Y: Candidate regions of tumor suppressor locus on chromosome 9q31.1 in gastric cancer. Int J Cancer 2004 109:71-75

21. Gryfe R, Swallow C, Bapat B, Redston M, Gallinger S, Couture J: Molecular biology of colorectal cancer. Curr Probl Cancer 1997 21:233-300

22. Yang L, Leung AC, Ko JM, Lo PH, Tang JC, Srivastava G, Oshimura M, Stanbridge EJ, Daigo Y, Nakamura Y, Tang CM, Lau KW, Law S, Lung ML: Tumor suppressive role of a 2.4 Mb 9q33-q34 critical region and DEC1 in esophageal squamous cell carcinoma. Oncogene 2005 , 24:697-705

23. Habuchi T, Yoshida O, Knowles MA: A novel candidate tumour suppressor locus at 9q32-33 in bladder cancer: localization of the candidate region within a single $840 \mathrm{~kb}$ YAC. Hum Mol Genet 1997 , 6:913-919

24. Ghaleb AM, Nandan MO, Chanchevalap S, Dalton WB, Hisamuddin IM, Yang VW: Kruppel-like factors 4 and 5: the yin and yang regulators of cellular proliferation. Cell Res 2005, 15:92-96

25. Wei D, Kanai M, Jia Z, Le X, Xie K: Kruppel-like factor 4 induces p27Kip1 expression in and suppresses the growth and metastasis of human pancreatic cancer cells. Cancer Res 2008, 68:4631-4639

26. Yoon HS, Yang VW: Requirement of Kruppel-like factor 4 in preventing entry into mitosis following DNA damage. J Biol Chem 2004 279:5035-5041

27. Yoon HS, Ghaleb AM, Nandan MO, Hisamuddin IM, Dalton WB, Yang VW: Kruppel-like factor 4 prevents centrosome amplification following gamma-irradiation-induced DNA damage. Oncogene 2005, 24 4017-4025

28. Zhao W, Hisamuddin IM, Nandan MO, Babbin BA, Lamb NE, Yang VW: Identification of Kruppel-like factor 4 as a potential tumor suppressor gene in colorectal cancer. Oncogene 2004, 23:395-402

29. Ohnishi S, Ohnami S, Laub F, Aoki K, Suzuki K, Kanai Y, Haga K, Asaka M, Ramirez F, Yoshida T: Down-regulation and growth inhibitory effect of epithelial-type Kruppel-like transcription factor KLF4, but not KLF5, in bladder cancer. Biochem Biophys Res Commun 2003, 308:251-256

30. Wei D, Kanai M, Huang S, Xie K: Emerging role of KLF4 in human gastrointestinal cancer. Carcinogenesis 2006, 27:23-31

31. Wei D, Gong W, Kanai M, Schlunk C, Wang L, Yao JC, Wu TT, Huang $\mathrm{S}$, Xie K: Drastic down-regulation of Kruppel-like factor 4 expression is critical in human gastric cancer development and progression. Cancer Res 2005, 65:2746-2754

32. Buckbinder L, Velasco-Miguel S, Chen $Y, X u$ N, Talbott R, Gelbert L, Gao J, Seizinger BR, Gutkind JS, Kley N: The p53 tumor suppressor targets a novel regulator of $G$ protein signaling, Proc Natl Acad Sci USA 1997, 94:7868-7872

33. Hong JX, Wilson GL, Fox CH, Kehrl JH: Isolation and characterization of a novel B cell activation gene. J Immunol 1993, 150:3895-3904

34. Siderovski DP, Heximer SP, Forsdyke DR: A human gene encoding a putative basic helix-loop-helix phosphoprotein whose mRNA increases rapidly in cycloheximide-treated blood mononuclear cells. DNA Cell Biol 1994, 13:125-147

35. Hruban RH, Goggins M, Parsons J, Kern SE: Progression model for pancreatic cancer. Clin Cancer Res 2000, 6:2969-2972

36. Hruban RH, Adsay NV, Albores-Saavedra J, Compton C, Garrett ES, Goodman SN, Kern SE, Klimstra DS, Kloppel G, Longnecker DS, Luttges J, Offerhaus GJ: Pancreatic intraepithelial neoplasia: a new nomenclature and classification system for pancreatic duct lesions. Am J Surg Pathol 2001, 25:579-586

37. Luttges J, Galehdari H, Brocker V, Schwarte-Waldhoff I, Henne-Bruns D, Kloppel G, Schmiegel W, Hahn SA: Allelic loss is often the first hit 
in the biallelic inactivation of the p53 and DPC4 genes during pancreatic carcinogenesis. Am J Pathol 2001, 158:1677-1683

38. Chatterjee TK, Eapen A, Kanis AB, Fisher RA: Genomic organization, 5'-flanking region, and chromosomal localization of the human RGS3 gene. Genomics 1997, 45:429-433

39. Koelle MR, Horvitz HR: EGL-10 regulates G protein signaling in the C. elegans nervous system and shares a conserved domain with many mammalian proteins. Cell 1996, 84:115-125

40. Druey KM, Blumer KJ, Kang VH, Kehrl JH: Inhibition of G-proteinmediated MAP kinase activation by a new mammalian gene family. Nature 1996, 379:742-746

41. Prasad NB, Biankin AV, Fukushima N, Maitra A, Dhara S, Elkahloun AG, Hruban RH, Goggins M, Leach SD: Gene expression profiles in pancreatic intraepithelial neoplasia reflect the effects of Hedgehog signaling on pancreatic ductal epithelial cells. Cancer Res 2005, 65:1619-26

42. Katz JP, Perreault N, Goldstein BG, Actman L, McNally SR, Silberg $\mathrm{DG}$, Furth EE, Kaestner KH: Loss of Klf4 in mice causes altered proliferation and differentiation and precancerous changes in the adult stomach. Gastroenterology 2005, 128:935-945

43. Dang DT, Mahatan CS, Dang LH, Agboola IA, Yang VW: Expression of the gut-enriched Kruppel-like factor (Kruppel-like factor 4) gene in the human colon cancer cell line RKO is dependent on CDX2. Oncogene 2001, 20:4884-4890

44. Fang DC, Luo YH, Yang SM, Li XA, Ling XL, Fang L: Mutation analysis of APC gene in gastric cancer with microsatellite instability. World $J$ Gastroenterol 2002, 8:787-791

45. Grace A, Butler D, Gallagher M, Al-Agha R, Xin Y, Leader M, Kay E: APC gene expression in gastric carcinoma: an immunohistochemical study. Appl Immunohistochem Mol Morphol 2002, 10:221-224

46. Godmann M, Kromberg I, Mayer J, Behr R: The mouse Kruppel-like Factor 4 (Klf4) gene: four functional polyadenylation sites which are used in a cell-specific manner as revealed by testicular transcript analysis and multiple processed pseudogenes. Gene 2005, 361 : $149-156$

47. Cordes KR, Sheehy NT, White MP, Berry EC, Morton SU, Muth AN, Lee TH, Miano JM, Ivey KN, Srivastava D: miR-145 and miR-143 regulate smooth muscle cell fate and plasticity. Nature 2009, 460: 705-710

48. Xu N, Papagiannakopoulos T, Pan G, Thomson JA, Kosik KS: MicroRNA-145 regulates OCT4. SOX2, and KLF4 and represses pluripotency in human embryonic stem cells. Cell 2009, 137:647658

49. Foster KW, Frost AR, McKie-Bell P, Lin CY, Engler JA, Grizzle WE, Ruppert JM: Increase of GKLF messenger RNA and protein expression during progression of breast cancer. Cancer Res 2000, 60: 6488-6495

50. Moral M, Segrelles C, Martínez-Cruz AB, Lorz C, Santos M, GarcíaEscudero R, Lu J, Buitrago A, Costa C, Saiz C, Ariza JM, Dueñas M, Rodriguez-Peralto JL, Martinez-Tello FJ, Rodriguez-Pinilla M Sanchez-Cespedes M, Digiovanni J, Paramio JM: Transgenic mice expressing constitutively active Akt in oral epithelium validate KLFA as a potential biomarker of head and neck squamous cell carcinoma. In Vivo 2009, 23:653-60

51. Harper JW, Adami GR, Wei N, Keyomarsi K, Elledge SG: The p21 Cdk-interacting protein Cip1 is a potent inhibitor of G1 cyclin-dependent kinases. Cell 1993, 75:805-816

52. Hu W, Hofstetter WL, Li H, Zhou Y, He Y, Pataer A, Wang L, Xie K, Swisher SG, Fang B: Putative tumor-suppressive function of Kruppellike factor 4 in primary lung carcinoma. Clin Cancer Res 2009, 15 5688-95

53. Marlow LA, Reynolds LA, Cleland AS, Cooper SJ, Gumz ML, Kurakata S, Fujiwara K, Zhang Y, Sebo T, Grant C, Mclver B, Wadsworth JT, Radisky DC, Smallridge RC, Copland JA: Reactivation of suppressed RhoB is a critical step for the inhibition of anaplastic thyroid cancer growth. Cancer Res 2009, 69:1536-1544 